\title{
Resistência Térmica de Cápsulas Contendo Os Microrganismos Probióticos Lactobacillus plantarum e Enterococcus faecium
}

\author{
Gabriela Poletto (I), Greice Carine Raddatz (I), Mariana de Araújo
} Etchepare (I), Maria Fernanda da Silveira Cáceres de Menezes (I), Augusto Tasch Holkem (I), Thaiane Marques da Silva (I), Caroline Posser Simeoni (I), Leadir Lucy Martins Fries (I), Carlos Pasqualin Cavalheiro (I), Cristiano Ragagnin de Menezes (I)

(I) UFSM - Universidade Federal de Santa Maria (Avenida Roraima)

\section{Resumo}

Entre os alimentos funcionais,destacam-se os probióticos que são microrganismos vivos que quando aplicados em quantidades suficientes promovem efeitos benéficos à saúde de quem os consome. Para que os probióticos exerçam sua função é indicado que a dose diária seja entre 8 e 9 $\log \mathrm{UFC} / \mathrm{g}$, sendo que a mínima concentração deve ser entre 6 e $7 \log$ UFC/g no momento do consumo. Por isso, é um grande desafio que os microrganismos mantenham-se viáveis durante o processamento e armazenamento dos alimentos, visto que muitos passam por condições extremas de temperatura como produtos pasteurizados e produtos cárneos cozidos. Assim, a técnica de encapsulação surge como uma alternativa para minimizar os danos provocados por temperaturas excessivas e permitir a incorporação de microrganismos probióticos em produtos cozidos. Foram utilizados Lactobacillus plantarum e Enterococcus faecium e material de cápsula contendo alginato de sódio (1\%), trealose (5\%), inulina (1\%) e leite em pó (1\%).A solução foi gotejada através de um encapsulador em solução de cloreto de cálcio $0.1 \mathrm{M}$. Após, $1 \mathrm{~g}$ de cápsulas foi adicionada em $9 \mathrm{ml}$ de água peptonada e submetida à $70^{\circ} \mathrm{C}$ e $80^{\circ} \mathrm{C}$ por 20 e 30 min e o plaqueamento feito em agar MRS. Os resultados mostram que o $\mathrm{L}$.

\footnotetext{
Referência:

Gabriela Poletto, Greice Carine Raddatz, Mariana de Araújo Etchepare, Maria Fernanda da Silveira Cáceres de Menezes, Augusto Tasch Holkem, Thaiane Marques da Silva, Caroline Posser Simeoni, Leadir Lucy Martins Fries, Carlos Pasqualin Cavalheiro, Cristiano Ragagnin de Menezes. Resistência Térmica de Cápsulas Contendo Os Microrganismos Probióticos Lactobacillus Plantarum e Enterococcus Faecium. In: Anais do 12을 Congresso Latinoamericano de Microbiologia e Higiene de Alimentos - MICROAL 2014 [= Blucher Food Science Proceedings, num.1, vol.1]. São Paulo: Editora Blucher, 2014. DOI 10.5151/foodsci-microal-162
} 
plantarum não apresentou resistência às temperaturas e tempos testados. As cápsulas apresentaram contagem de 11,28 $\log \mathrm{UFC} / \mathrm{g}$ antes do tratamento térmico, porém após, os resultados foram inferiores a $6 \mathrm{log} \mathrm{UFC/g}$ para todos os tratamentos térmicos. Em relação ao E. faecium, as cápsulas foram resistentes ao tratamento térmico a $70{ }^{\circ} \mathrm{C}$ por 20 e $30 \mathrm{~min}$. Antes do tratamento térmico, as cápsulas apresentaram contagens de E. faecium de 13,56 log UFC/g. Após 20 minutos a $70^{\circ} \mathrm{C}$, os valores foram de 13,16 log UFC/g e após 30 minutos a $70^{\circ} \mathrm{C}$, os valores foram de 12,65 log UFC/g. No entanto, apesar da redução nas contagens não houve diferenças significativas entre os tratamentos. Porém, ao elevar a temperatura a $80^{\circ} \mathrm{C}$, as cápsulas não apresentaram resistência térmica, com valores inferiores a 6 $\log$ UFC/g tanto a 20 minutos quanto a 30 minutos. Assim, a utilização de cápsulas probióticas de alginato de sódio, trealose, inulina e leite em pó contendo E. faecium pode ser uma alternativa para aplicação em produtos onde se utilize durante o processamento temperaturas de até $70^{\circ} \mathrm{C}$ por um período de até 30 minutos.

Palavras-Chave: Enterococcus faecium , Lactobacillus plantarum, microencapsulação, probióticos, resistência térmica

Agência de Fomento: 